\title{
37. DRY-BULK DENSITY: ITS USE AND DETERMINATION ${ }^{1}$
}

\author{
Kathleen A. Dadey, ${ }^{2}$ Tom Janecek, ${ }^{3}$ and Adam Klaus ${ }^{4}$
}

\begin{abstract}
Sediment dry-bulk density values are essential components of mass accumulation rate calculations. This manuscript presents three equations to calculate dry-bulk density from laboratory measurements of physical properties that have been corrected for the salt content of the pore fluid. In addition, two equations for use with values not corrected for salt content are included. Derivations of the equations from first principles are presented.

The second part of the manuscript briefly examines laboratory measurements of the various properties used in the dry-bulk density equations. A discussion of the problems inherent in the density measurements and recommendations are included. This work represents the first comprehensive compilation of equations of dry-bulk density and should prove useful to all scientists who investigate accumulation rates.
\end{abstract}

\section{INTRODUCTION}

The dry-bulk density of a sedimentary deposit is a necessary component of any accumulation rate calculation (e.g., mass accumulation rate $=$ linear sedimentation rate $\bullet$ dry-bulk density). Mass accumulation rates incorporate the effects of depositional and postdepositional processes and sediment composition. Gravitational compaction is the primary postdepositional process affecting sediment porosity (and consequently dry-bulk density), but other processes such as early diagenetic changes (e.g., cementation and authigenic mineral formation) may also result in significant changes in the porosity of the deposit. Consequently, dry-bulk density values may provide additional information and actually prove more useful than sedimentation rates for mass balance calculations. Nevertheless, in the past, most studies involving accumulation rates used dry-bulk density data in an inconsistent fashion, generally not explaining its origin (i.e., providing a basic definition), or, in some cases, presenting an inaccurate one.

This note will present six equations used to calculate dry-bulk density and will discuss the limitations of each. In addition, we will evaluate the specific measurements and methods used by the Ocean Drilling Program (through Leg 126) in the calculation of dry-bulk density.

\section{DRY-BULK DENSITY CALCULATIONS}

Dry-bulk density is defined as the mass (weight) of the dry solids divided by the total volume of the wet sample; that is, dry-bulk density is the ratio of the mass of the mineral grains to the total volume. All index properties are essentially ratios of masses and volumes. Therefore, drybulk density can be calculated directly from mass and volume measurements, or by relationships with other index properties.

We also separate our calculations into two basic types on the basis of pore fluid composition: (1) those concerned with samples containing pore waters composed of fresh or distilled water, and (2) those containing saline fluids. As calculations involving fresh water are less complicated, we begin with these.

\footnotetext{
Taylor, B., Fujioka, K., et al.. 1992. Proc. ODP, Sci. Results, 126: College Station, TX (Ocean Drilling Program).

${ }^{2}$ Graduate School of Oceanography, University of Rhode Island, Narragansett, RI 02882, U.S.A.

${ }^{3}$ Ocean Drilling Program, Texas A\&M University, College Station, TX 77845-9547, U.S.A.

${ }^{4}$ Department of Geology and Geophysics, Universaity of Hawaii, 2525 Correa Road, Honolulu, HI 96822, U.S.A. (pesent address: Ocean Research Institute, University of Tokyo, 1-15-1 Minamidai, Nakano, Tokyo 164, Japan).
}

\section{Fresh (Distilled Water) Pore Fluid}

The simplest (and most direct) equation for calculating dry-bulk density employs the mass and volume measurements in the definition, that is, the mineral mass and the total volume. When the pore fluid consists of fresh (distilled) water, the mass of the mineral solids is equal to the mass of the dry sample. Total volume equals the wet volume. Consequently, the first equation for dry-bulk density is

$$
\rho_{\mathrm{d}}=\mathrm{M}_{\mathrm{s}} / \mathrm{V}
$$

in which $\rho_{d}=$ dry-bulk density, $M_{s}=$ the mass of the dry sample (weight of the solid portion of the sample), and $\mathrm{V}=$ the total volume (volume of the wet sample).

Mass and volume data are not always available, so we present other equations that employ more easily accessible parameters. These parameters include porosity $(\phi)$, grain density $\left(\rho_{s}\right.$; or grain specific gravity, which is defined as the ratio of the mass of the mineral grains to the mass of an equal volume of fresh water; in the cgs system, it is numerically equal to grain density), water content ( $w c=\%$ dry weight; $w_{c}{ }^{*}=\%$ wet weight $)$, wet-bulk density $\left(\rho_{w}\right)$, and density of the pore fluid ( $\rho f)$, a value which can be calculated from the composition of the pore fluid. In all these calculations, we assume that the sample is saturated; that is the pore spaces are completely filled with fluid. As a consequence, the volume of the pore spaces is equal to that of the pore fluid.

The equations that result from these parameters are

$$
\begin{gathered}
\rho_{d}=(1-\phi) \rho_{s}, \\
\rho_{d}=\rho_{w} /\left(1+w_{c}\right), \text { and } \\
\rho_{d}=\rho_{w}-\left(\rho_{f} \cdot \phi\right) .
\end{gathered}
$$

To derive Equation 2 from first principles, we define $M$ (total [wet] mass) $=M_{s}+M_{f}$, with $M_{s}=$ mass of solid grains and $M_{f}=$ mass of pore fluid; $\mathrm{V}=$ total volume, with $\mathrm{V}_{\mathrm{s}}=$ volume of solid grains and $\mathrm{V}_{\mathrm{f}}$ $=$ volume of void space (i.e., the volume of pore fluid); $\rho_{w}=M / V ; \phi$ $=\mathrm{V}_{\mathrm{p}} \mathrm{N} ;$ and $\rho_{\mathrm{s}}=\mathrm{M}_{\mathrm{s}} / \mathrm{V}_{\mathrm{s}}$. Therefore,

$$
(1-\phi)=\left(1-V_{f} / V\right)=\left(V-V_{f} / V\right) \text {. }
$$

Because $V-V_{f}=V_{s}$, then

$$
\mathrm{r}_{\mathrm{s}}(1-\phi)=\mathrm{M}_{\mathrm{s}} / \mathrm{V}_{\mathrm{s}}\left(\mathrm{V}_{\mathrm{s}} / \mathrm{V}\right)=\mathrm{M}_{\mathrm{s}} / \mathrm{V}=\rho_{\mathrm{d}} .
$$

Equations 3 and 4 may be derived in the same manner. Solving for Equation 3 gives the following: 


$$
\begin{gathered}
\left(1+w_{c}\right)=1+M_{f} / M_{s}=\left(M_{s}+M_{f}\right) / M_{s} \text { and } \\
\left(1+w_{c}\right) \cdot\left(1 / \rho_{w}\right)=\left(\left[M_{s}+M_{f}\right] / M_{s}\right) \cdot\left(V /\left[M_{s}+M_{f}\right]\right)=V / M_{s} .
\end{gathered}
$$

Therefore,

$$
r_{w} /\left(1+w_{c}\right)=M_{s} / V=\rho_{d} .
$$

Similarly for Equation (4),

$$
\begin{gathered}
\left(\rho_{f} \cdot \phi\right)=\left(M_{f} / V_{f}\right) \cdot\left(V_{f} / V\right)=M_{f} / V \text { and } \\
r_{w}-\left(\rho_{f} \cdot \phi\right)=\left(\left[M_{s}+M_{f}\right] / V\right)-M_{f} / V=\left(M_{s}+M_{f}-M_{f}\right) / V \\
=M_{s} / V=\rho_{d} .
\end{gathered}
$$

\section{Saline Pore Fluid}

The presence of saline pore waters in marine deposits is a potentially significant complication to dry-bulk density calculations. Salt crystals, originally dissolved in the pore fluid, remain as solids after drying, because only fresh water is evaporated. Consequently, dry weight and volume measurements include this salt, resulting in erroneous values. A comprehensive discussion of the equations required to correct for the salinity of pore fluids may be found in Noorany (1984) and are summarized here. The basic calculation subtracts the weight of this remaining salt from the measured dry weight of the sample. The resulting corrected dry weight is

$$
M_{s}=M-M_{f}=\left(M_{d}-s M\right) /(1-s),
$$

in which $M$ and $M_{s}$ were defined previously, $M_{f}=$ the mass of the salt water, $\mathrm{M}_{\mathrm{d}}=$ the uncorrected dry mass, and $\mathrm{s}=$ salinity (expressed as a decimal; i.e., $35 \mathrm{ppt}=0.035$ ).

This mass value then can be used in subsequent index property calculations. Therefore, when samples with saline pore fluid are measured, one needs to know mass and volume measurements to calculate dry-bulk density, unless the derived parameters have already been corrected for salt content. In these cases, the salt-corrected values can be input directly into Equations 2, 3, or 4. For uncorrected values, we can derive the following, using basic index property definitions (Lambe and Whitman, 1969) and the value of saltcorrected dry mass (Eq. 5).

$$
\begin{gathered}
\rho_{d}=\left(M_{d}-s M\right) / V(1-s) \text { and } \\
\rho_{d}=\rho w /\left(\left[1+w_{c}\right] /\left[1-s-s w_{c}\right]\right) .
\end{gathered}
$$

In these equations, $\mathrm{w}_{\mathrm{c}}=$ uncorrected water content $=\mathrm{M} / \mathrm{M}_{\mathrm{s}}$.

\section{MEASUREMENTS}

\section{Leg 126 Data}

A maximum of four measurements are required to calculate drybulk density: total wet weight (mass), dry weight, total wet volume, and dry volume. Measurement of wet and dry weights is straightforward, with the accuracy and precision of the measurements being dependent primarily on the accuracy and precision of the balance employed. One source of variability in weight measurements is the drying method. Oven drying at $110^{\circ}+0.5^{\circ} \mathrm{C}$, for $24 \mathrm{hr}$, the accepted American Society for Testing and Materials standard (ASTM, 1989) was used on Leg 126. This temperature is sufficient to evaporate pore water and water adsorbed to clay particle surfaces, but not high enough to affect clay interlayer water. Some forms of labile organic matter can be driven off at temperatures as low as $60^{\circ} \mathrm{C}$, however, resulting in inaccurate dry weights. Therefore, freeze-drying is preferred in samples with high organic contents. High humidity also can affect weights if dried samples are able to absorb moisture from the air. We recommend that samples be weighed stored in a desiccator until the dried samples have cooled to room temperature.

The volume measurement is a much less direct technique. On board the JOIDES Resolution, a pycnometer is used routinely to determine wet and dry volumes. This method is quick and is specified to a precision of $0.5 \%$ (Quanta-chrome, 1987). The pycnometer relies on Archimedes' principle of fluid displacement to determine the sample volume. Helium (He) is used as the displaced fluid, as the small gas molecules can penetrate into very small pore spaces. The pycnometer, however, was designed to measure volumes of dry, granular solids, such as powders, not wet sediment samples, and suspicions of inaccurate measurements were expressed as early as Leg 110 (Wilkens et al., 1990). Inconsistencies in the index property data were noted on Leg 126 as well. As a result, we undertook several experiments to evaluate the source of these anomalous data.

Measurement of solid-metal calibration standards resulted in accuracy and precision better than $1 \%$. It has been suggested (Shipboard Scientific Party, 1988) that inaccuracies observed previously in wetsample volumes might result from gas-water interactions. To test this theory, we completed a series of measurements in which known aliquots of either distilled or salt water were added to a solid metal standard and the combined volume measured (Fig. 1). Volume increases measured after the addition of both types of fluid are linear. The slopes of the two relationships are not quite unity, suggesting the possibility of some interaction. The deviations are quite small, however, and generally the data indicate no direct interaction between the He gas and the pore fluid.

The pycnometer was also used to measure wet and dry volumes of a sandstone sample that had been cut into a cube. The cube's volume was also calculated from measurements of the lengths of the sides of the cube using calipers. Pycnometer dry-volume measurements are less than those measured with calipers, suggesting that the pycnometer gas does penetrate into the sample. Wet volumes determined with the pycnometer also were lower than the caliper volumes, however. Because we assume that wet volume is equal to the total volume of the wet sample, these data raise doubts as to the accuracy of the wet-volume measurements. Some evaporation of pore fluid from the surface of the sample between sampling and measurement may occur, as a result of the coarse-grained nature of sandstone, but the difference between the caliper and pycnometer measurements is over $9 \%$, higher than we expect for surface evaporation only. This discrepancy suggests that the $\mathrm{He}$ gas is actually displacing some of the pore fluid,

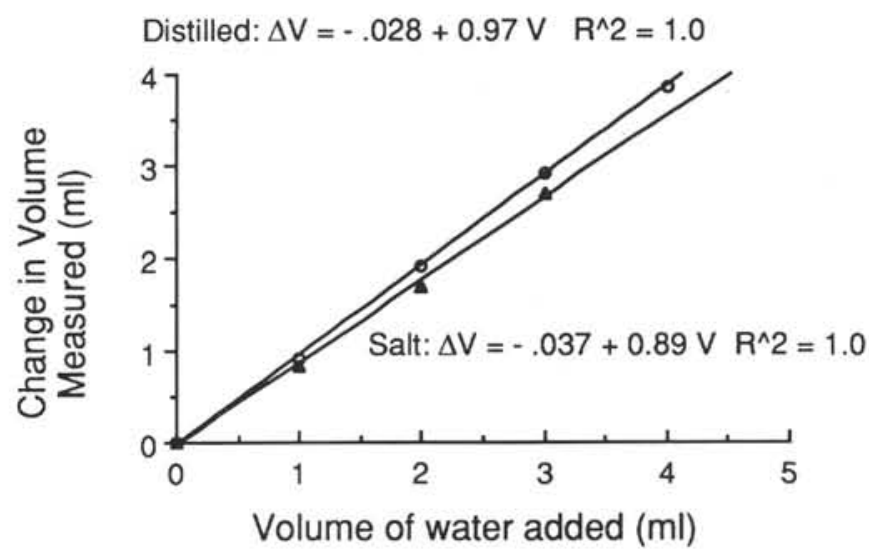

Figure 1. Change in volume measured by the Penta-pycnometer vs. volume of fluid added to solid-metal calibration standards. Open circles $=$ distilled water, and solid triangles = salt water. Note that although perfect correlation coefficients exist for the two relationships, the correspondence, as indicated by the slopes, between volume measured and volume added is, in both cases, slightly less than $1: 1$. 
resulting in underestimation of the wet volume. A similar underestimation of wet volumes has been noted in carbonate-rich samples (O'Brien, 1990).

Comparison of the volumes measured with respect to time also suggests that the purge time specified by the manufacturer (1 min; Quanta-Chrome, 1987) as well as that recently suggested in standard ODP procedures ( $3 \mathrm{~min}$; K. Moran, pers. comm., 1987) may not be long enough, particularly for wet consolidated samples. The drysample volume appears to peak at $5 \mathrm{~min}$, then decline slightly; the wet-sample volume does not even begin to stabilize until after approximately $10 \mathrm{~min}$ of purge time (Fig. 2).

The high porosity and low bulk density of the pumiceous sediments recovered on Leg 126 made this material a good candidate for our experiments. Two different pumice samples were subjected to different preparation techniques (essentially different degrees of crushing), and their volumes were measured with the pycnometer (Fig. 3). The data indicate that for individual samples, the smaller the relative grain size, the smaller the measured volume and, therefore, the larger the calculated density. We suspect that crushing the sample increased the degree of interconnected pore space, allowing the He to permeate the sample more completely. Although this may not be a problem with unconsolidated sediments, many of the lithologies encountered on Leg 126 and other ODP legs are semilithified. Because we did not routinely crush the dried index property samples on Leg 126, the volume of dried samples may be underestimated and the grain density overestimated.

We also examined values of specific gravity determined postcruise by an accurate gravimetric pycnometer technique (e.g. Bowles, 1978). We compared these values to shipboard pycnometer-determined grain densities to evaluate possible correction of the shipboard pycnometer values. Two thirds of the samples tested exhibited average pycnometer-derived grain density values less than the average measured specific gravity (Table 1). A direct relationship with a correlation coefficient of 0.9 results when we examine values measured by both methods over the entire range of densities (Fig. 4). This relationship, however, is based entirely on a single sample with low grain density and low specific gravity. Those samples exhibiting grain densities between 2.65 and 2.8 (eight of the nine tested) suggest no such relation (Fig. 4). These results suggest that pycnometer-determined volumes cannot be corrected routinely using specific gravity data.

Finally, we measured the grain density of two substances with known densities, $\mathrm{NaCl}$ (salt) and $\mathrm{CaCO}_{3}$ (calcium carbonate). These substances are dry, granular solids. The resulting densities of 2.22 and $3.33 \mathrm{~g} / \mathrm{cm}^{3}$ are $2 \%$ and $23 \%$ greater than accepted values, respectively (Johnson and Olhoeft, 1984; Smith, 1974). The density of $\mathrm{NaCl}$ is within the estimated error of the weight and volume measurements. The error associated with the $\mathrm{CaCO}_{3}$ grain density, on the other hand, is much greater than that which would be expected from measurements alone. Clearly, a more extensive investigation of the methods of measuring weights and volumes on ODP legs is warranted.

\section{DISCUSSION AND RECOMMENDATIONS}

We have presented six equations for calculating dry-bulk density that employ either raw data (weights and volumes) or calculated parameters (porosity, water content, wet-bulk density, and grain density). We have also included equations for calculating dry-bulk density for samples with saline pore fluids.

Our examination of the current ODP method for measuring volumes, the pycnometer, suggests that the accuracy of the measurements declines significantly if the sample is other than a dry, unconsolidated, fine-grained material. Our results suggest that the prime cause of inaccuracies in dry lithified samples is the inability of the $\mathrm{He}$ to penetrate all the pore spaces. In addition, if the pores are not

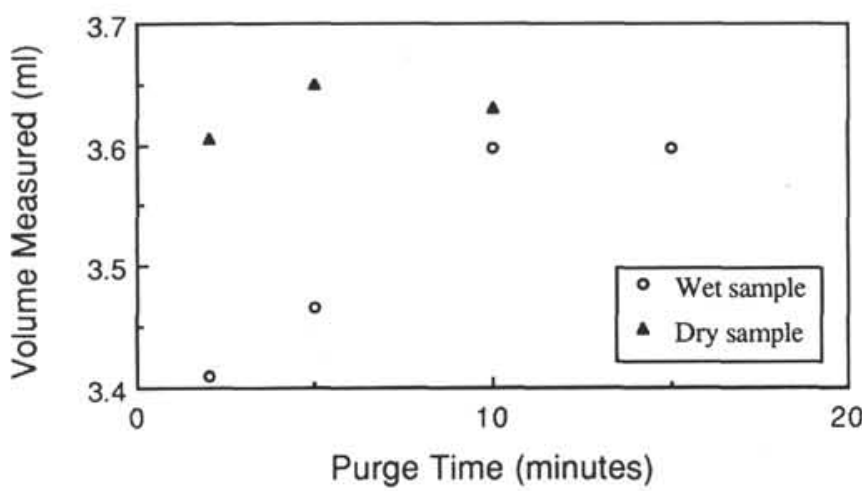

Figure 2. Volume measured in the Penta-pycnometer vs. purge time for a sandstone sample tested both wet and dry. Open circles = wet sample, and solid triangles $=$ dry sample.
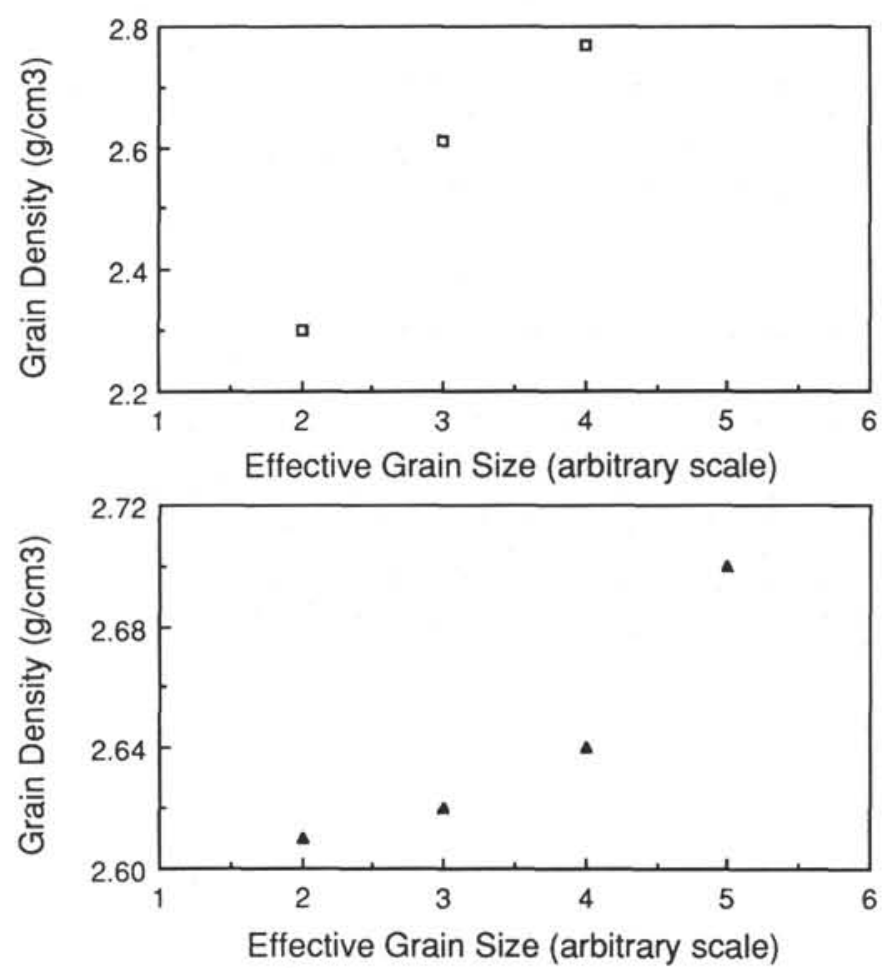

Figure 3. Grain density calculated from pycnometer volume measurements of two pumice samples that were subjected to different degrees of crushing (i.e., increased crushing decreases the effective grain size).

all interconnected, the gas will not reach some of the pore spaces. The apparent penetration of $\mathrm{He}$ into external pores originally filled with pore fluid in wet samples is also a source of inaccuracy. Our experiments are not sufficient to quantify the degree of loss of accuracy; however, based on our results, we recommend some modifications to the current ODP procedure for measuring volumes:

1. increase the pycnometer purge time to at least $5 \mathrm{~min}$ to obtain the most accurate volume;

2. whenever possible, crush dry samples to increase the interconnectedness of the pores; and

3. avoid the use of wet-volume measurements in index property calculations. 


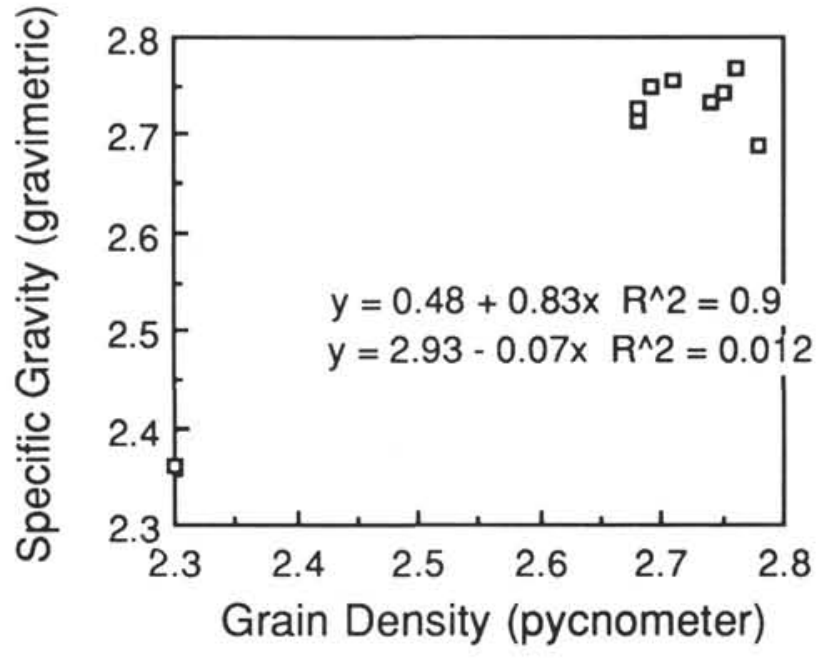

Figure 4. Specific gravity values from shore-based laboratory analyses vs. grain density measurements completed on board the JOIDES Resolution. The high correlation coefficient in the top equation is misleading because it relies entirely on the single low grain density point; a coefficient of 0.012 results when we examine the data without this point.

\section{REFERENCES}

American Society for Testing and Materials, 1989. Annual Book of ASTM Standards (Part 19): Natural Building Stones: Soil and Rock: Philadelphia (ASTM).

Bowles, J. E., 1978. Engineering Properties of Soils and Their Measurement: New York (McGraw-Hill).

Johnson, G., and Olhoeft, G., 1984. Density of rocks and minerals. In Carmichael, R. (Ed.), CRC Handbook of Physical Properties of Rocks (Vol. III): Boca Raton, FL (CRC Press).

Lambe, T. W., and Whitman, R. V., 1969. Soil Mechanics: New York (Wiley). Noorany, I., 1984. Phase relations in marine soils. J. Geotech. Eng., 110:539-543.
Table 1. Gravimetric- and pycnometer-determined density values.

\begin{tabular}{ccc}
\hline $\begin{array}{c}\text { Core, section, } \\
\text { interval }(\mathrm{cm})\end{array}$ & $\begin{array}{c}\text { Average specific } \\
\text { gravity }\left(\mathrm{g} / \mathrm{cm}^{3}\right)\end{array}$ & $\begin{array}{c}\text { Average grain } \\
\text { density }\left(\mathrm{g} / \mathrm{cm}^{3}\right)\end{array}$ \\
\hline 126-790C- & & \\
10X-2, 34-36 & 2.69 & 2.78 \\
13X-3,98-100 & 2.75 & 2.69 \\
16X-5, 91-93 & 2.74 & 2.75 \\
19X-6, 71-73 & 2.71 & 2.68 \\
126-791A- & & \\
5H-4, 24-26 & 2.77 & 2.76 \\
23H-2,71-72 & 2.36 & 2.30 \\
126-791B- & & \\
25R-1, 27-29 & 2.76 & 2.71 \\
40R-3,54-56 & 2.73 & 2.74 \\
47R-1, 28-30 & 2.73 & 2.68 \\
\hline
\end{tabular}

Notes: Specific gravity values were determined by standard gravimetric techniques in the shore-based laboratory; grain densities were determined using the Penta-pycnometer onboard the JOIDES Resolution.

O'Brien, D. K., 1990. Physical, acoustic, and electrical properties of deep-sea sediments [Ph.D. dissert.]. Univ. Hawaii.

Quanta-Chrome Corporation, 1987. Penta-Pycnometer Manual. (unpubl.).

Shipboard Scientific Party, 1988. Introduction and explanatory notes. In Becker, K., Sakai, H., et al., Proc. ODP, Init. Repts., 111: College Station, TX (Ocean Drilling Program), 5-22.

Smith, F.G.W. (Ed.), 1974. Handbook of Marine Science (Vol. 1): Cleveland, $\mathrm{OH}$ (CEC Press).

Wilkens, R., McLellan, P., Moran, K., Tribble, J. S., Taylor, E., and Verduzco, E., 1990. Diagenesis and dewatering of clay-rich sediments, Barbados accretionary prism. In Moore, J. C., Mascle, A., et al., Proc. ODP, Sci. Results, 110: College Station, TX (Ocean Drilling Program), 309-320.

Date of initial receipt: 30 October 1990

Date of acceptance: 1 October 1991

Ms 126B-157 